\title{
Fulfilment of technical and hygienic requirements among street food vendors in Slovenia
}

Street food vendors in Slovenia

\author{
Vanja Prevolšek, Andrej Ovca and Mojca Jevšnik \\ Department of Sanitary Engineering, Faculty of Health Sciences, \\ University of Ljubljana, Ljubljana, Slovenia
}

\begin{abstract}
Purpose - This cross-sectional study aimed to evaluate the compliance of hygienic and technical standards of street food vendors in Slovenia with the requirements of the general hygienic food principals set in the Codex Alimentarius and Regulation (EC) No. 852/2004 on the hygiene of foodstuffs.

Design/methodology/approach - Food vendors were observed directly and discretely using a semistructured observation sheet that allowed fast evaluation. The employee's behaviour was not affected during the observations because they were not aware of being observed. Each observation lasted approximately $30 \mathrm{~min}$. Food vendors were divided into groups according to their location, type of facility, number of employees and type of food sold.

Findings - Depending on the type of street vendor, more inconsistencies were found amongst food stands compared to food trucks and kiosks. Most food trucks and kiosks scored very high in both personal and hygienic-technical standards. Some of the major inconsistencies were lack of suitably located washbasins, improper hand-washing technique, improper waste management, working surfaces that were inadequately separated from consumers, and inconsistent maintenance of the cold chain. Food handlers have been confirmed as a critical risk factor.

Research limitations/implications - Despite methodology validation, the data was collected by a single observer, limiting the ability to obtain a more reliable estimate of the observations. The sample was disproportionate according to the type of street food facilities.

Practical implications - The results provide a basis for (1) national professional guidelines of good hygiene practices for food business operators, which should cover street food vendors more extensively in future updates, and (2) the development of food safety training programmes tailored for street vendors.

Originality/value - The study provides valuable insights into current hygienic-technical conditions of the street food vending sector.
\end{abstract}

Keywords Street food, Mobile vendors, Food safety, Good hygienic practices, Discrete observation

Paper type Research paper

\section{Introduction}

According to the Food and Agriculture Organization (FAO), 2.5 billion people consume street food daily (Fellows and Hilmi, 2011). "Street foods are ready-to-eat foods and beverages prepared and/or sold by vendors and hawkers especially in streets and other similar public places" (Rane, 2011, p. 100). Street food vending is tremendously popular in both developing and developed countries. Vendors can be found in almost every corner of the street, market, city centre, or any other public place, where the ebb and flow of people going about their daily lives is substantial (Proietti et al., 2013). The final preparation of precooked food typically

(C) Vanja Prevolšek, Andrej Ovca and Mojca Jevšnik. Published by Emerald Publishing Limited. This article is published under the Creative Commons Attribution (CC BY 4.0) licence. Anyone may reproduce, distribute, translate and create derivative works of this article (for both commercial and noncommercial purposes), subject to full attribution to the original publication and authors. The full terms of this licence may be seen at http://creativecommons.org/licences/by/4.0/legalcode

The authors acknowledge the financial support from the Slovenian Research Agency (research core funding No. P3-0388). The authors would also like to express their gratitude to Terry Jackson for language corrections.

Received 25 November 2020 Revised 3 February 2021 4 March 2021

Accepted 4 March 2021 
BFJ

123,13

occurs immediately after the consumer has ordered the meal. Once the consumer receives his meal, he or she can consume it immediately or at a later time without further processing or preparation (WHO, 1996). The food can be prepared for consumption from an open-air stand, cart, truck, or even a market stand. The street food phenomenon has become an indispensable component of food distribution systems, mainly because it is physically and economically accessible. It also enables consumers to save a significant amount of time (Kotzekidou, 2016; Kumar Gupta et al., 2017a).

Street food is very similar to home-cooked food. It often reflects the traditional local culture since its preparation is often based on local cooking traditions. For most tourists, it is one of the best ways to experience the real culture of any region (Ab-Karim and Geng-Qing Chi, 2010). In addition to its cultural value, street food enables people to meet their daily nutritional needs as it provides a wide range of nutrients. Its nutritional value depends on the ingredients and the way they are prepared and processed. A comprehensive survey in Bangkok revealed that street food on average provides $40 \%$ of the daily energy intake, $39 \%$ of the daily protein intake, and $44 \%$ of the daily iron intake for all age groups (FAO, 2007). A significant nutritional contribution of street food was also observed in a cross-sectional study of 1,172 Vietnamese adolescents. Street food consumption represented $42 \%$ of fruits and vegetables, $23 \%$ of sodium, $21 \%$ of energy, $21 \%$ of vitamin A, $21 \%$ of iron, and $21 \%$ of zinc that they consumed on a daily basis (Lachat et al., 2009).

Despite numerous benefits, it is recognised that street food may pose major public health risks (WHO, 1996; FAO, 2007). Lack of basic infrastructure, inadequate potable water supplies, poor personal hygiene and mishandling of food play a significant role in the occurrence of foodborne illnesses (WHO, 1996; Kumar Gupta et al., 2017a). According to the official reports from the European Food Safety Authority, 21 foodborne strong-evidence outbreaks related to mobile retailers or street vendors were confirmed in the last eight years. The outbreaks resulted in 164 cases and two deaths. Two foodborne outbreaks, each responsible for one fatal case, were reported to be caused by Listeria monocytogenes. These Listeria strong-evidence cases were associated with the consumption of crab. Other foodborne outbreaks were reported to be caused by either Salmonella, Calicivirus including norovirus, histamine or bacterial toxins (other than Clostridium botulinum). The most frequently reported contributory factors for the strong-evidence outbreaks were an unprocessed contaminated ingredient, improper hand-washing practices, and crosscontamination (EFSA and ECDC, 2015a, b; 2016; 2017; 2018; 2019). The occurrences of foodborne illnesses confirm that street food vendors are faced with various challenges when attempting to secure the safety of their food.

An exploratory study of the microbiological quality of street vending food that examined the food handlers' hygiene status has shown that insufficient personal hygiene may result in poor microbiological quality and safety of street food. Food handlers have been recognised as a critical risk factor in the food vending sector. The study showed that all food and food handlers' hands samples were contaminated with Enterobacteriaceae and coliforms. $44 \%$ of food handlers also carried coagulase-positive staphylococci (Campos et al., 2015).

Sabbithi et al. (2017) established that a large number of carrot $(98.1 \%)$ and onion $(75.5 \%)$ samples were contaminated with $E$. coli during food preparation by street food handlers of Hyderabad, India. The results of the study by Elobeid et al. (2019) showed that fast food handlers had poor knowledge of the proper cleaning of equipment, cross-contamination prevention, foodborne diseases, food temperature danger zone and correct procedures for thawing frozen food. Only $34.7 \%$ of the food handlers correctly identified Salmonella as a food pathogen.

Based on European legislation, food business operators should establish and implement food safety programmes based on Hazard Analysis and Critical Control Point (HACCP) principles to ensure that food safety is not compromised (Regulation, 2004). Maintaining good 
hygienic practices is considered to be a great approach to comply with food hygienictechnical requirements (Kumar Gupta et al., 2017a). Any person who directly handles food is therefore expected to maintain a high degree of personal hygiene. It is also a necessity that they maintain proper behaviour and have enough knowledge of how to handle food hygienically. With safe food-handling techniques, the microbiological cross-contamination of food can be prevented and, with it, the majority of foodborne illnesses (Buliyaminu, 2016; Campos et al., 2015; Al Mamun et al., 2013).

The current cross-sectional study aimed to evaluate the compliance of the hygienic and technical standards of street food vendors in Slovenia with the requirements of the general hygienic food principals set in the Codex Alimentarius and Regulation (EC) No. 852/2004 on the hygiene of foodstuffs. The compliance rate was investigated according to the vendor type, vendors` location, and number of employees.

\section{Material and methods}

\subsection{Research protocol}

Observations were conducted from April to June 2018. Food vendors were observed directly and discretely using a semi-structured observation sheet that enabled a quick evaluation. Each observation lasted approximately $30 \mathrm{~min}$. The employee's behaviour was not affected during the observations because they were not aware of being observed. As a result, they did not abandon certain activities, change their behaviour, or perform more consistently than otherwise. The chair of environmental health approved the research protocol.

The street food vendors were divided into groups according to their location (city centre or tourist point outside the city centre), type of facility (food trucks, kiosks, food stands), type of food sold (meat or fish meals, vegetarian meals, sale of fresh fruit or vegetable and mixed meals (e.g. meat meals and desserts), gender and number of employees (one, two, three or more).

As part of the current study, 48 street food vendors from different parts of the country (representing $23 \%$ of all registered street food vendors in Slovenia according to the Slovenian Business Register) were conveniently sampled (we were limited to those food vendors who were present on the day of the observation). The research subjects were the vendors' facilities in two city centres and two tourist points outside the city centre.

\subsection{Observation sheet}

The observation sheet (Table A1) was divided into three sections. In Section 1, information about the street food vendors' general characteristics was recorded. In Section 2, the hygienic-technical criteria of equipment, food preparation and food serving process were evaluated through 16 criteria. In Section 3, personal hygiene requirements for employees handling food were evaluated through 11 criteria. The evaluation criteria were prepared following the Codex Alimentarius and Regulation EC No. 852/2004 on the hygiene of foodstuffs (2004).

Hygienic-technical requirements and personal hygiene requirements were evaluated at the time of observations using the same grading scale as previously used by Trafialek et al. (2017). The grading scale contained four grades (2, 3, 4 and 5). By not having a clearly defined centre, the grading scale forces the observer to consider the assessment thoroughly. The highest grade (5), corresponded to the fulfilment of requirement (100\% compliance), and the lowest one (2), indicated non-compliance (less than $40 \%$ compliance). It was assumed that 5 was the only grade that ensured that the final product was safe for consumers from a food safety standpoint. A slight deviation from the requirement was evaluated with Grade 4 ( $80 \%$ compliance). Finally, Grade 3 meant that the requirement was not met properly (60\% compliance), and food safety was not assured. 
$\mathrm{BFJ}$

123,13

The grading scale was validated in a test observation of three conveniently selected street food vendors. The validation was carried out by the first author of this paper and two other auditors (second and third author of this paper) who are experienced in food hygiene and knowledgeable about food safety and food quality management in the food industry. All three researchers compared their results after independent assessment and discussed discrepancies to reach a consensus.

\section{8}

\subsection{Data analysis}

The data were evaluated and analysed using the Statistic Program for the Social Sciences (SPSS, Version 24.0, Chicago, IL, 2006). Mean grades, median, mode and standard deviation were used to characterise the level and distribution of grades. Mean grades for each type of food facility and each requirement are recalculated into mean compliance (\%). The obtained values correspond to the three propriety levels of food safety risk. High (40-60\% compliance) where food safety is not assured; medium ( $60 \%-80 \%$ compliance) where food safety is questionable and low (80-100\% compliance) where despite minor nonconformities, the food is still safe for consumption. To examine the relationships between the vendors' location and the number of employees with obtained grades, an independent $t$-test was applied. Additionally, two major categories were formed during data analysis: 1 - the total average grade of all hygienic-technical requirements and 2 - the total average grade of all personal hygiene requirements. The relationships were characterised as significant when the calculated $p$-value was less than 0.05 .

\section{Results}

\subsection{Street vendors' general characteristics}

Depending on the type of facilities, mainly food stands $(81.2 \%)$, followed by food trucks $(10.4 \%)$ and kiosks $(8.3 \%)$ were included in the observations. Food trucks and kiosks $(n=9)$ offered different kinds of meat in $62.5 \%$ and fish meals in $37.5 \%$ of cases. In contrast, food stands $(n=39)$ provided meat or fish meals in $59 \%$, vegetarian meals in $23 \%$, fresh fruit or vegetable meals (e.g. fresh smoothie) in $5 \%$ and mixed meals (meat meals and/or vegetable meals and/or desserts) in $13 \%$ of cases.

\subsection{Hygienic-technical requirements}

A comparison of the street vendors revealed many differences with regard to fulfilling the hygienic-technical requirements. Street food trucks and kiosks met them with better compliance compared to street food stands (Table 1). The critical issue in this regard was the inadequate supply of potable water. Street food stands met this requirement with an average compliance of $52 \%$. Another observed shortcoming of food stands was the inadequate use of fixtures that are used to prevent light sources from shattering into small glass particles $(60 \%$ compliance). Such protection is needed because it ensures that the food will not become contaminated by glass particles in case of breakage.

Fifty-two per cent of vending facilities were inadequately equipped with containers dedicated to waste separation. Food waste that came into contact with food was not always removed from the working surfaces as soon as it should have been (Table 1); 38\% of food stands deposited waste into polyethylene bags and stored them on the ground, next to foodprocessing surfaces. In almost half of other cases, containers were not closable, which also posed potential hazards for contamination by pests. Although waste disposal was improper, pigeons were observed only around surrounding areas of a few food trucks (94\% compliance). 


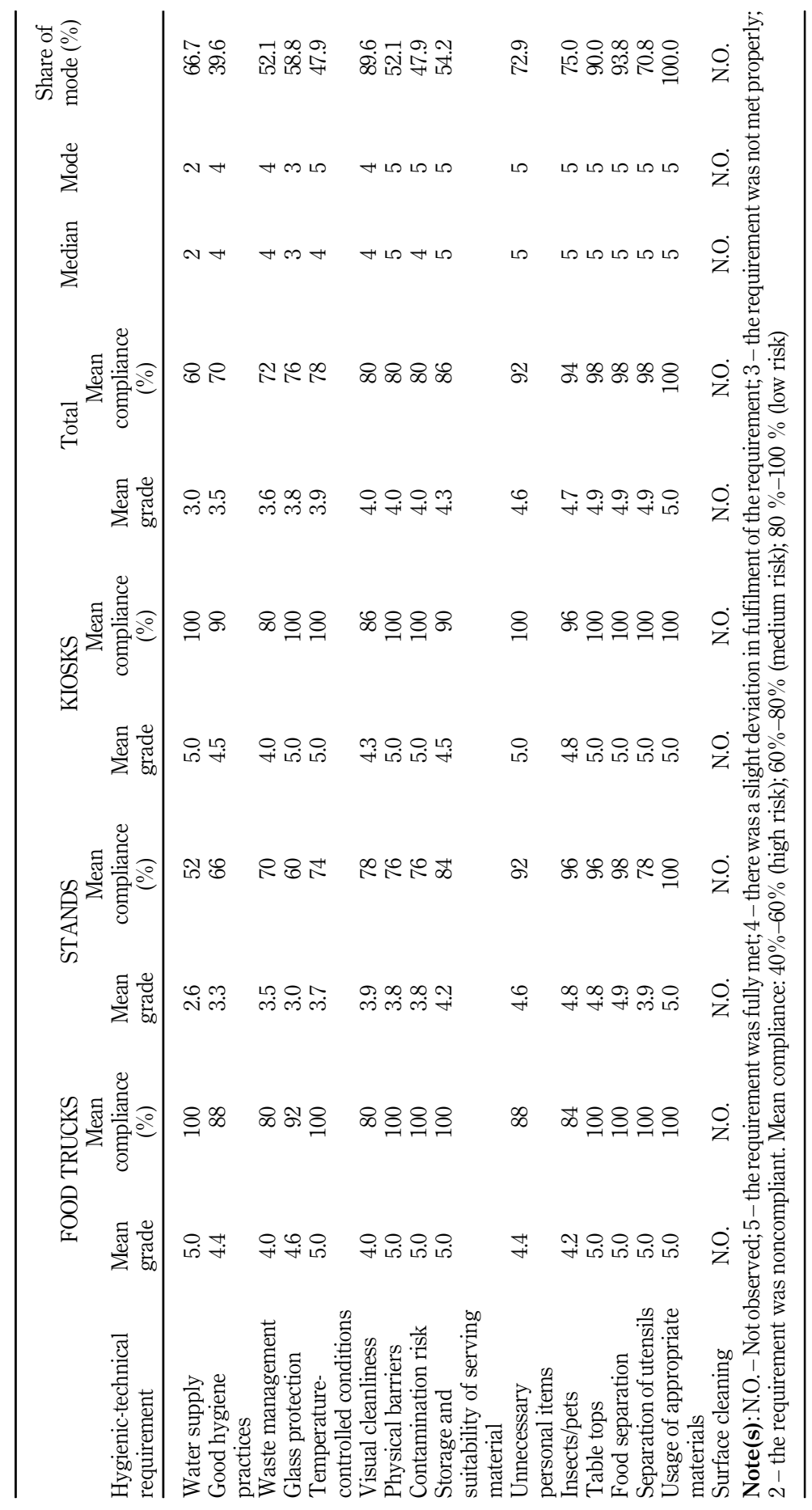

Street food vendors in Slovenia

Table 1

Meeting the hygienictechnical requirements based on vendors' type 
BFJ

123,13

110

Equipment, utensils and working surfaces that came into contact with food were generally made out of smooth, suitable materials, which are inert when used with food and are easy to clean and disinfect. However, $10 \%$ of food stands working surfaces were not non-absorbent. In such cases, wet cleaning or disinfection cannot be done efficiently. The foods were properly served in disposable plastic or wooden packagings. In $46 \%$ of facilities, serving materials were not stored separately from the food-processing surfaces. Consequently, the materials were exposed to a risk of contamination. A statistically significant $(\phi<0.05)$ difference between meeting the suitable serving material storage requirement and vendors' location was determined. Facilities located in city centres met the requirement with greater compliance (Figure 1).

According to Regulation (EC) No. 852/2004, potential sources of contamination from the environment should always be considered. In particular, food-processing areas should be protected with physical barriers from consumers. In 59\% of food stands' processing areas, there was a probability of cross-contamination from consumers' coughs, sneezes or direct hand contact. In some cases, improving the employees' hygiene-related behaviour patterns has been recognised as crucial. Personal items, such as mobile phones, wallets, purses, keys and cigarettes, were present on the food handling surfaces at the time of observations. In $40 \%$ of all cases related to food trucks and food stands, mobile phones were used during food handling procedures, and in one case, smoking was also observed.

Considering food separation, the degree to which the requirements were fulfilled was optimal in the case of food trucks and kiosks (Table 1). Raw foods and ready-to-eat foods were stored separately at controlled temperature conditions and kept in visually clean, food-grade storage containers. Equipment and utensils were used separately in a correct manner at all stages of food preparation. In contrast, major noncompliances with the refrigerated storage of high-risk foodstuffs and cross-contamination were all observed in the case of food stands. Providing temperature-controlled handling and storage conditions for maintaining foodstuffs at the appropriate temperature was not fulfilled in $52 \%$ of all food stand cases. This particular requirement was assessed with the lowest average grade (Table 1). Consistent maintenance of the cold chain was performed by two food stands. Intended use of equipment and utensils was inconsistent (Table 1). Cross-contamination of raw and hot-treated meat or processed foods and contaminated utensils was observed in $18 \%$ of all observed cases. Based on a visual assessment, hot-treated foods were maintained and served to the consumers at high temperatures.

Due to all the instances of non-compliance, food stands met the requirement of good hygiene practices with an overall compliance of $66 \%$ (Table 1). Food trucks and kiosks consistently complied with principles of good hygiene practices. The calculated mean grade indicated a compliance level of $90 \%$. The results of the independent samples $t$-test revealed some statistically significant $(p<0.05)$ differences with regard to the number of employees. Vendors with fewer (one or two) employees better met the requirements of temperaturecontrolled conditions, cross-contamination risks and good hygienic practices (Figure 2).

\subsection{Personal hygiene requirements}

In total, 127 food handlers' hygiene status and food handling techniques, of which 81 males $(64 \%)$ and 46 females $(36 \%)$, were evaluated during the observation sessions. Food trucks and kiosks employees' that came into contact with food met the personal hygiene requirements with better compliance than employees of food stands did (Table 2). A lack of suitably located washbasins and improper hand-washing and/or hand-drying techniques were the main deviations observed. Unlike food stands, food trucks and kiosks had washbasins appropriately located at their workplace, but the non-compliance to requirements for both hygienically washing and drying hands indicated their improper implementation. 


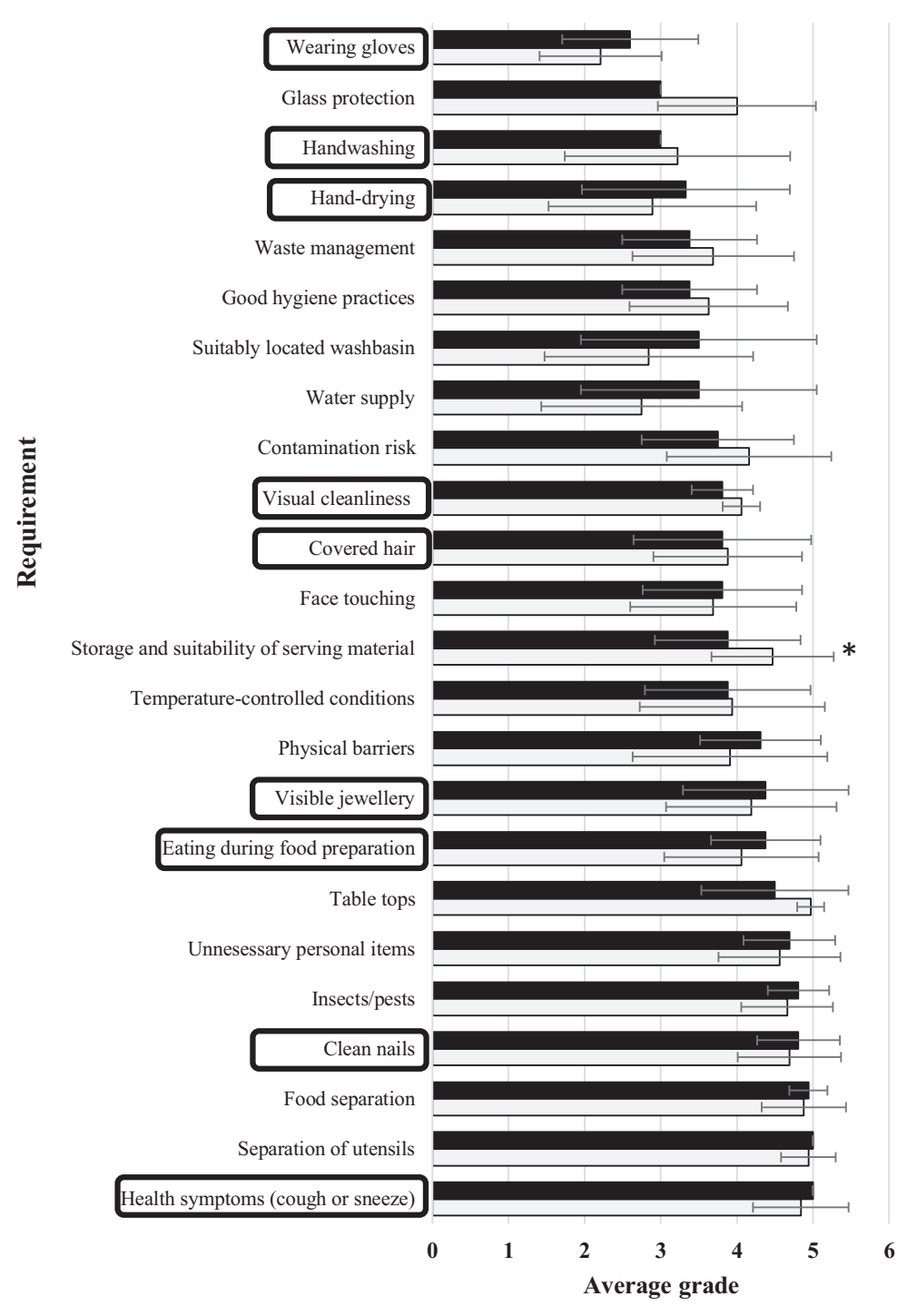

- Tourist site $\square$ City center

Note(s): *Statistically significant difference $(p<0.05)$;
Personal hygiene requirment

\section{Street food vendors in Slovenia}

Figure 1. Average grades and standard deviations of meeting the hygienetechnical and personal hygiene requirements based on the vendors' location

Specifically, food handlers did not wash their hands in a correct hygienic manner, as they did not always use soap and water (Table 2). In total, $61 \%$ of observed food handlers wiped their hands onto working clothes or non-disposable towels that were also used for contact with foods and utensils. The score of 2 was received by $53 \%$ of street food vendors.

Another concern regarding hand hygiene was the inappropriate usage of gloves observed among $40 \%$ of the street stands food handlers. In most cases, the use of disposable gloves was 
BFJ

123,13

\section{2}

Figure 2.

Average grades and standard deviations of meeting the hygienetechnical and personal hygiene requirements based on the number of employees

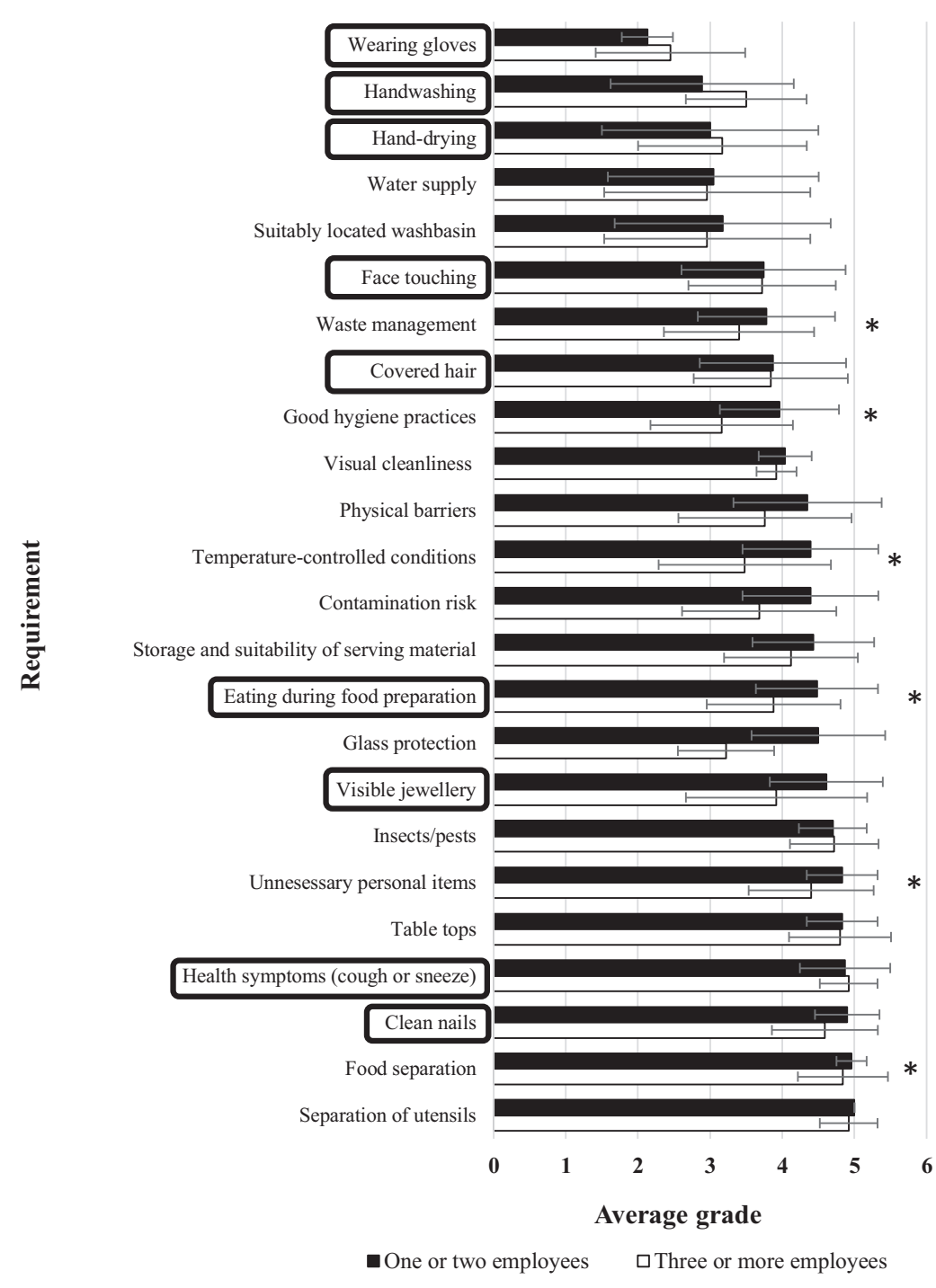

Note(s): *Statistically significant difference $(p<0.05)$; Personal hygiene requirment

inconsistent. Gloves were not used exclusively for a particular food task and were usually used for longer periods. The requirement was fulfilled with a compliance level of $46 \%$ (Table 2). In this regard, food safety was questionable (mode 2, the share of mode $84 \%$ ). Unlike food stands, food trucks' and kiosks' food handlers fulfilled the requirement with a compliance level of $100 \%$ (Table 2).

Even though food handlers should be aware of their responsibility to protect food from contamination, half of the observed food handlers (54\%) engaged in food handling activities have not refrained from behaviour which could result in contamination of food by smoking, 


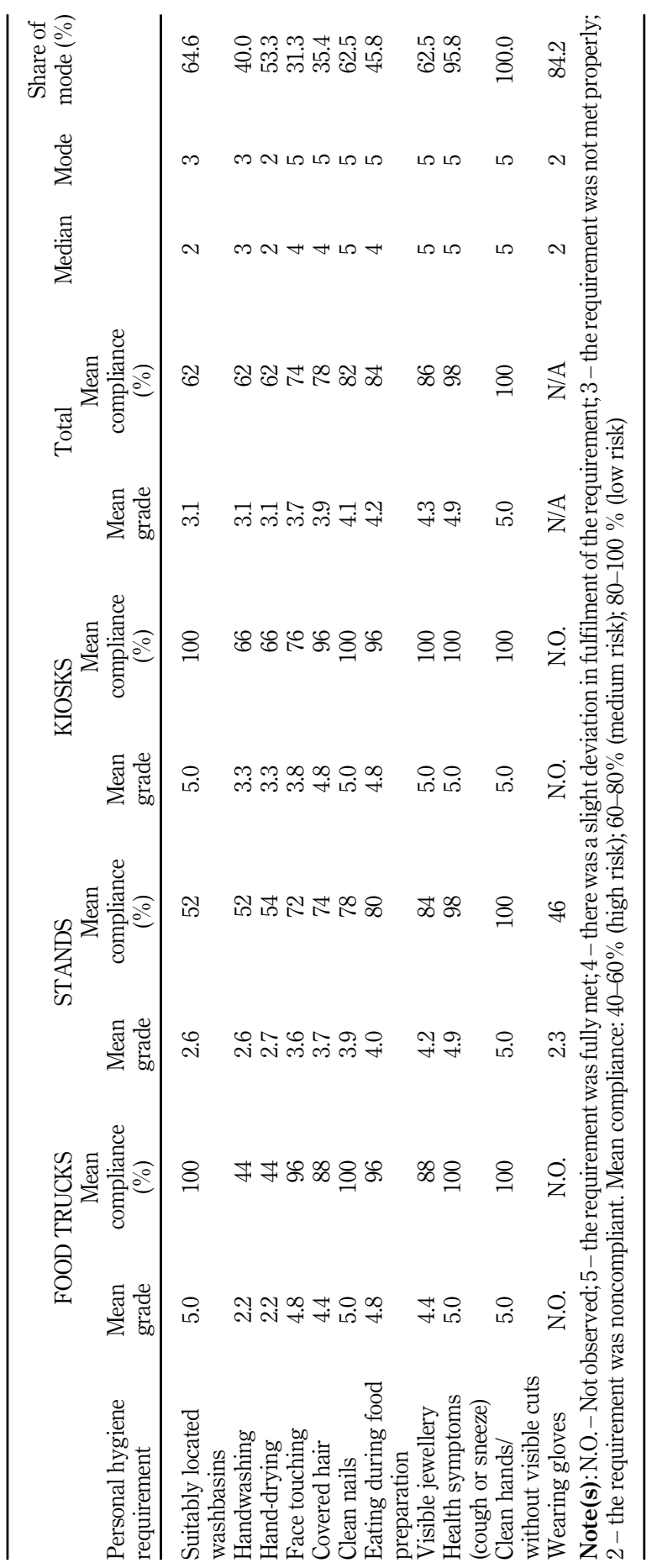

Street food vendors in Slovenia

113

Table 2.

Meeting the personal hygiene requirements based on vendors' type 
$\mathrm{BFJ}$

123,13

114

drinking, chewing gum, or eating during the working processes (Table 2). Statistically significant $(\phi<0.05)$ higher ratings were received by vendors with fewer (one or two) employees (Figure 2). Non-compliance with regards to visible jewellery or artificial nails has demonstrated that this requirement was not respected by food handlers. Visible jewellery, including watches and artificial nails (among females), were present by $43 \%$ of food handlers, mostly by street food stand employees that were in contact with food. The fulfilment of the requirement was optimal among male food handlers in food kiosks (Table 2). Because hair covering equipment was in used only among $7 \%$ of food handlers, the requirement was instead assessed by looking at the hair length and frequency of hair-touching during the food process. This requirement was fulfilled with a compliance of $74 \%$ (Table 2 ). The mean grade was below the mode and median. The mode score 5 was received by $35 \%$ of street food vendors.

An appropriate degree of the health status requirement was fulfilled exceptionally in the section about personal hygiene (Table 2). Discharges from the nose, sneezes, or coughs were observed in $5 \%$ of all cases. Handlers' hand skin was not visibly infected. Hands of all observed food workers were free of wounds, cuts and other skin disease symptoms.

\subsection{The impact of vendors' type, location and number of employees}

Results analysed according to the vendor type demonstrate a higher compliance rate among food trucks and kiosks in comparison to stands. However, in all three vendor types compliance with personal hygiene requirements (Table 1) presents a bigger food safety risk than with hygiene-technical requirements (Table 2). Regardless of the vendors' location and number of employees, the highest risk for food safety is related to the human factor, particularly hand hygiene seen in the improper use of protective gloves, and insufficient hand washing and hand drying (Figure 1 and 2). The most critical technical requirement which depends on vendors' type is the inadequate supply of potable water amongst food stands (Table 1).

Although the fulfilment of requirements does not differ significantly related to the vendors' location (Figure 1), some more impact is observed in relation to the number of employees (Figure 2). A detailed comparison demonstrates that a higher number of people involved in food operations results in lower compliance in hand hygiene aspects (Figure 2). All significant differences related to the number of employees indicate that bigger vendors with more employees also have more difficulty meeting the requirements.

\section{Discussion}

Based on the European Regulation (EC) No. 852/2004 on the hygiene of foodstuffs, food business operators are responsible for ensuring minimum hygiene conditions and measures that are necessary to guarantee the safety and suitability of food to consumers (Regulation, 2004). Our study with discrete observations resulted in a snapshot of current hygienictechnical and personal hygiene conditions of small street food businesses. Depending on the type of vendor, the food business operators of food stands had more difficulties in ensuring minimum hygienic-technical conditions than the food business operators of food trucks and kiosks. Major noncompliances (e.g. inadequate supply of potable water, non-use of lighting fixtures, improper waste management, absence of un-positioned physical barriers in front of the consumer, and inconsistent maintenance of the cold chain) were all results of deficient infrastructure.

According to FAO recommendations, mobile vendors should not be located far from adequate water supply (FAO, 2009). Current study has revealed that the unavailability of potable water for various activities at the vendors' immediate vicinity is of great concern. 
Food stands had exclusive access to washbasins in only $20 \%$ of cases, while food trucks and kiosks had exclusive access to washbasins in $100 \%$ of cases. Trafialek et al. (2018) came to a similar conclusion: out of all 440 inspected mobile and/or temporary street food vendors, only $40.9 \%$ had an acceptable source of potable water (among them, mobile cart bikes were rated with the lowest average grade).

An example of good practice in the current study is the installation of temporary washbasins with a supply hot and cold potable water near the food vending facilities, which should not be accessible by consumers. Potable water is essential for frequent washing of hands, of food, for cleaning utensils, and also for drinking and as an ingredient in food. Due to its' many potential uses, vendors tend to re-use water, especially for foodstuffs and hand washing or cleaning of utensils, which can be critical from a microbiological food safety point of view as reported by others (Proietti et al., 2013; Trafialek et al., 2018). Despite the inaccessibility of washbasins, water was not re-used during our observations in the current study.

A comparison of the use of fixtures that prevent light sources from shattering into small glass particles showed no difference in meeting this requirement if we compare our results and those of Trafialek et al. (2017). This specific requirement was not significantly influenced by the vending location in the current study, while Trafialek et al. (2017) reported that facilities located in city centres received the highest ratings in this regard.

Good hygiene practice requires appropriate waste management. Suitable provision should be made for all stages of waste handling (separation, removal and storage) (NIPH, 2014). In general, street food vendors in the current study did not separate the waste once it was produced. Waste from food processing was conspicuously accumulated on food handling surfaces and/or was disposed of close to the stand sites. Unhygienic waste disposal could pose potential hazards for cross-contamination by attracting insects or other pests (NIPH, 2014; Trafialek et al., 2017). For example, flies and pigeons can transmit infectious agents (e.g. Salmonella spp. and E. coli). Trafialek et al. (2018) concluded that the consistency of waste management is fully related to the scope of work, which depends on the frequency of consumers and the diversity of food offered.

Even though street food vendors are usually located in more congested places, all food handling activities should be performed under high standards of hygiene. In particular, temporary mobile premises with no walls, such as street food stands, should consider potential sources of contamination from the environment (air, dust, water, pests, etc.) in detail. Consumers who can easily access food-processing areas represent an important source of outdoor contamination. The positioning of a non-permanent physical barrier is thus essential (Proietti et al., 2013). During the process of food distribution, one common non-compliance observed in the current study was the lack of complete separation between food and consumers. Furthermore, processed food, stored on food stands' tabletops, was not covered with suitable material or stored in closed containers, which increased the significant risk for food contamination from the environment.

Overall, street food vendors in the current study serviced by fewer (one or two) employees met the hygienic-technical requirements with better compliance. Based on the result, we have concluded that the degree of compliance may be related to the type of vendor. In particular, food trucks and kiosks have better basic technical conditions, and those types of vendors were mostly serviced by fewer (one or two) employees. The level of the hygienic-technical requirements was not significantly influenced by the food vending location.

Regardless of whether the food is partially pre-prepared at home or entirely on the street, safe food handling procedures have to be implemented (Al Mamun et al., 2013). Street food handling procedures include hygienic food storage, food preparation, cooking, reheating, cooling and distributing (NIPH, 2015). To avoid cross-contamination, raw foods have to be stored away from other foods, especially cooked foods and ready-to-eat foods (NIPH, 2014).
Street food vendors in Slovenia 
BFJ

123,13

116

A slight deviation in meeting the requirement of safe food separation was identified during the observations in the current study. Cross-contamination of raw and cooked meat was observed in one case, related to the food stands. Another non-strict separation between raw meat and fresh vegetables was also observed in the case of a food stand. In such cases, food safety is not assured. The final dish could be contaminated with pathogens (e.g. L. monocytogenes, Salmonella spp., B. cereus or C. perfringens). The improper separation of unprocessed and cooked foods was also reported in some other EU countries. For example, in Italy, small food businesses are facing problems with the lack of complete food separation and inappropriate storage conditions (Legnani et al., 2004). The temperature is especially essential when it comes to food storage (NIPH, 2015). In this regard, the requirement of temperaturecontrolled conditions was assessed with the lowest average grade. Inconsistent maintenance of the cold chain, while storing raw meat in sealed containers under food stand tabletops, completely unprotected from the sunlight, indicated a low level of knowledge and a lack of food-handling skills in the current study. Constantly opening refrigerator doors and direct exposure to sunlight could crucially reduce the efficiency of refrigerators' operation. Given the above, safe temperature storage conditions were most probably not assured. The temperature above $25{ }^{\circ} \mathrm{C}$ is favourable for bacterial growth and histamine formation. Consumption of fish or fish products contaminated with large amounts of histamine can lead to histamine poisoning, also known as scombroid food poisoning (Proietti et al., 2013).

The current study has also shown that personal hygiene requirements were not fully implemented. Hygiene principles were violated due to improper hand hygiene. The main discrepancies were improper hand-washing, unhygienic usage of gloves, and face touching. The same noncompliances were confirmed by other authors in both developed and developing countries (e.g. Portugal (Campos et al., 2015), Greece, Poland, Thailand, China (Trafialek et al., 2018) and the USA (FDA, 2018)). Non-use of soap during hand washing could result in the faecal contamination of food as confirmed by Sabbithi et al. (2017), who also reported that samples from vendors with hand jewellery were highly contaminated compared to those who did not wear it during food production. Disposable gloves can be used as a tool for the prevention of cross-contamination when used correctly (i.e. only for a specific task and for a short period). However, the risk of bacterial transmission and the occurrence of foodborne illness is still higher if the gloves are used incorrectly than if they are not used at all (Trafialek et al., 2018). Most food stand employees did not use food-handling gloves according to the recommendations for safe food handling usage. In other words, food handlers did not understand that disposable gloves are not an adequate substitution for hand-washing.

As reported by others (Trafialek et al., 2018; FDA, 2018), the inconsistent performance of hand hygiene is one of the most frequently observed unhygienic practices among food handlers. Trafialek et al. (2018) discovered that $36.4 \%$ of food vendors met the hand-washing criteria, with $40 \%$ of compliance or less. A one-year survey on the occurrence of foodborne illness risk factors due to non-compliance with good hygiene practices in the United States restaurant settings, including street food facilities revealed that $66.6 \%$ of settings did not comply with basic food hygiene principles. Among risk factors, they also pointed out poor hand hygiene, especially inadequate time and/or improper execution (FDA, 2018). In addition to inadequate time and improper execution, the neglect of this hygienic measure was often noted in the current study. Even though good hand-washing technique is the most effective way to prevent the spreading of contamination, hands were often not washed after performing unclean working procedures. Unlike food stands, food trucks and kiosks had suitably located washbasins, but the hand hygiene was also unsatisfactory. The main reasons for violating hand-hygiene practice were limited levels of knowledge, awareness and insufficient training of employees that were in contact with food. The latter can only be assumed based on the findings of previous studies (Roever, 2014; Samapundo et al., 2014; Kumar Gupta et al., 2017b; Asiegbu et al., 2015) since the food handlers' knowledge and 
awareness were not assessed in the current study. As reported by others (Samapundo et al., 2014; Asiegbu et al., 2015; Elobeid et al., 2019), vendors and consumers are often aware of the importance of washing hands with regards to the prevention of foodborne diseases, but the majority of them have difficulties in identifying foodborne pathogens that are responsible for foodborne diseases (Hepatitis A, Salmonella spp., and Staphylococcus spp.). The existence of insufficiently educated or untrained food handlers poses a potential threat to the safety of food and its suitability for consumption (Jevšnik et al., 2008). Highly trained vendors are better at engaging in food handling activities and have superior attitudes compared to untrained vendors (Samapundo et al., 2014). More in-depth training is thus a vital element of food safety programmes for any food hygiene system (Roever, 2014; Kotzekidou, 2016). As suggested by the FDA (2018), the presence and constant supervision of the food business operators can significantly improve the hygienic-behavioural patterns of employees. In addition to supervision, Kotzekidou (2016) states that the process of certifying could be a great approach for identifying appropriately trained street food vendors. By selecting a certified food vendor, consumers would gain greater confidence in the safety and quality of street food (Kotzekidou, 2016). Another effective approach to improving bad hygiene practices among food handlers is to incorporate food safety and hygiene lessons into primary school programmes (Al Mamun et al., 2013). Educating children on food hygiene and food safety in primary schools is crucial because human behaviour is more easily influenced at that age (Ovca et al., 2019). That way, not only food handlers' but also consumers' would receive basic food-hygiene knowledge (Al Mamun et al., 2013). Additionally, consumers would become more critical when choosing and purchasing food. Criticism is a powerful incentive that forces food handlers to eliminate potential unhygienic food-handling practices (Kotzekidou, 2016).

\section{Conclusions}

In the present cross-sectional study, the compliance of the hygienic and technical standards of street food vendors in Slovenia with the general hygienic food principals' requirements was evaluated. The revealed situation highlighted that human factors play a major role in food safety assurance in this sector. The management of human factors and the fulfilment of personal hygiene requirements present bigger challenges for the food business operators than fulfilling hygiene-technical requirements regardless of vendors' location and the number of employees.

Depending on the type of street vendor, more inconsistencies were found amongst food stands than among mobile food trucks and kiosks. Most food trucks and kiosks scored very high in both personal and hygienic-technical standards. Some of the major inconsistencies were lack of suitably located washbasins, improper hand-washing technique, inadequate protection from shattering glass particles of light sources, improper waste management, working surfaces that were inadequately separated from consumers and inconsistent maintenance of the cold chain.

There is a need to change incorrect hygiene-related behaviour patterns, which can be achieved with a systematic approach, regular employees' training, and constant active surveillance of the employees' personal hygiene and food handling techniques. Existing national professional guidelines of good hygiene practices for food business operators should, therefore, pay more attention to street food vendors as part of the future updates. Additionally, specific and street vendor tailored food safety training programmes should be developed and delivered. Moreover, official food safety authorities should regularly check their implementation in practice. Although this paper is based on a focused study, it clearly shows that even well-defined hygiene tools need regular and permanent food handler training.
Street food
vendors in
Slovenia 
BFJ

123,13

118

\section{Research limitations}

The data were collected by a single observer, limiting the ability to obtain a more reliable estimate of the observations. The sample of the research was conveniently selected on the days, the observations were carried out, as the location of the mobile, and temporary facilities cannot be determined in advance. Consequently, according to the type of street food facilities, the sample was disproportionate. Testing the level of knowledge, cleanliness of surfaces, utensils, hands and microbiological quality of foods in combination with observations could provide more reliable data on the hygienic-technical and personal hygiene conditions of mobile, and temporary facilities, but one of the study purposes was not to affect employees' behaviour.

\section{References}

Ab-Karim, S. and Geng-Qing Chi, C. (2010), "Culinary tourism as a destination attraction: an empirical examination of destinations' food image", Journal of Hospitality Marketing and Management, Vol. 19 No. 6, pp. 53-555.

Al Mamun, M., Rahman, M. and Turin, C. (2013), "Microbiological quality of selected street food items vended by school-based street food vendors in Dhaka, Bangladesh", International Journal of Food Microbiology, Vol. 166 No. 3, pp. 413-418.

Asiegbu, V.C., Lebelo, L.S. and Tabit, T.F. (2015), "The food safety knowledge and microbial hazards awareness of consumers of ready-to-eat street-vended food”, Food Control, Vol. 60, pp. $422-429$.

Buliyaminu, A.A. (2016), "Risk factors in street food practices in developing countries: a review", Food Science and Human Wellness, Vol. 5 No. 3, pp. 141-148.

Campos, J., Gil, J., Mourão, J., Peixe, L. and Antunes, P. (2015), "Ready-to-eat street-vended food as a potential vehicle of bacterial pathogens and antimicrobial resistance: an exploratory study in Porto region, Portugal”, International Journal of Food Microbiology, Vol. 206, pp. 1-6.

EFSA and ECDC (2015a), "The European union summary report on trends and sources of Zoonoses, Zoonotic agents and food-borne outbreaks in 2013", EFSA Journal, Vol. 13 No. 1, p. 67.

EFSA and ECDC (2015b), "The European Union summary report on trends and sources of Zoonoses, Zoonotic agents and food-borne outbreaks in 2014”, EFSA Journal, Vol. 13 No. 12, p. 190.

EFSA and ECDC (2016), "The European Union summary report on trends and sources of Zoonoses, Zoonotic agents and food-borne outbreaks in 2015”, EFSA Journal, Vol. 14 No. 12, p. 231.

EFSA and ECDC (2017), "The European Union summary report on trends and sources of Zoonoses, Zoonotic agents and food-borne outbreaks in 2016", EFSA Journal, Vol. 15 No. 12, p. 210.

EFSA and ECDC (2018), "The European Union summary report on trends and sources of Zoonoses, Zoonotic agents and food-borne outbreaks in 2017”, EFSA Journal, Vol. 16 No. 12, p. 240.

EFSA and ECDC (2019), "The European Union summary report on trends and sources of Zoonoses, Zoonotic agents and food-borne outbreaks in 2018”, EFSA Journal, Vol. 17 No. 12, p. 222.

Elobeid, T., Savvaidis, I. and Ganji, V. (2019), "Impact of food safety training on the knowledge, practice, and attitudes of food handlers working in fast-food restaurants", British Food Journal, Vol. 121 No. 4, pp. 937-949.

FAO (2007), "Promises and challenges of the informal food sector in developing countries. Food and agriculture organization of the United Nations (FAO), agricultural economics and engineering department, University of Bologna, Italy, and department of sociology and anthropology, University of ottawa, Canada, Rome", available at: http:/www.fao.org/3/a1124e/a1124e00.htm (accessed 3 August 2020).

FAO (2009), "Good hygienic practices in the preparation and sale of street food in africa. Tools for training. Food and agriculture organization of the United Nations (FAO). Rome, Italy", available at: http://www.fao.org/3/a0740e/a0740e00.htm (accessed 6 August 2020). 
FDA (2018), "FDA report on the occurrence of foodborne illness risk factors in fast food and full-service restaurants, 2013-2014. food and drug administration (FDA), U.S. department of health and human services, April 12, 2018, 5001 Campus Drive, College Park, MD 20740", available at: https://www.fda.gov/media/117509/download (accessed 27 October 2020).

Fellows, P. and Hilmi, M. (2011), "Selling street and snack foods: FAO diversification booklets No. 18, Rural infrastructure and agro-industries division, food and agriculture organization of the United Nations, Rome 2011”, available at: http://www.fao.org/3/i2474e/i2474e00.pdf (accessed 6 August 2020).

Jevšnik, M., Hlebec, V. and Raspor, P. (2008), "Food safety knowledge and practices among food handlers in Slovenia", Food Control, Vol. 19 No. 12, pp. 1107-1118.

Kotzekidou, P. (2016), "Food hygiene and toxicology in ready-to-eat foods", in Al - Mamun, M. and Chowdhury Turin, T. (Eds), Safety of Street Foods, 125 London Wall, Academic Press/Elsevier, London EC2Y 5AS, pp. 15-29.

Kumar, G.R., Dudeja, P. and Singh Minhas, A. (2017a), "Food safety in the 21st century: public health perspective", in Malhotra, S. (Ed.), Food Safety Issues Related to Street Vendors. 125 London Wall, Academic Press/Elsevier, London EC2Y 5AS, pp. 395-402.

Kumar, G.R., Dudeja, P. and Singh Minhas, A. (2017b), "Food safety in the 21st century: public health perspective", in Dudeja, P. and Singh Minhas, A. (Eds), Food Handlers. 125 London Wall, Academic Press/Elsevier, London EC2Y 5AS, pp. 269-280.

Lachat, C., Khanh, L.N.B., Khan, N.C., Dung, N.Q., Do Van Anh, N., Roberfroid, D. and Kolsteren, P. (2009), "Eating out of home in Vietnamese adolescents: socioeconomic factors and dietary associations", American Journal of Clinical Nutrition, Vol. 90 No. 6, pp. 1648-1655.

Legnani, P., Leoni, E., Berveglieri, M., Mirolo, G. and Alvaro, N. (2004), "Hygienic control of mass catering establishments, microbiological monitoring of food and equipment", Food Control, Vol. 15 No. 3, pp. 205-211.

NIPH - National Institute of Public Health of the Republic of Slovenia (2014), "Basic hygienic recommendations for food handlers", available at: https:/www.nijz.si/sites/www.nijz.si/files/ uploaded/osnovna_higienska_stalisca_nov_2014.pdf (accessed 22 September 2020).

NIPH - National Institute of Public Health of the Republic of Slovenia (2015), "Hygienic recommendations for food handlers, part 2", available at: https://www.nijz.si/sites/www.nijz. si/files/datoteke/higienska_stalisca_za_higieno_zivil_namenjena_delavcem_v_zivilski_ dejavnosti_2._stopnja_2014_verzija_2.pdf (accessed 22 September 2020).

Ovca, A., Jevšnik, M. and Raspor, P. (2019), "Challenges and strategies in the education of primary school children related to microbiological food safety - a review", International Journal of Sanitary Engineering Research, Vol. 13 No. 1, pp. 25-38.

Proietti, I., Frazzoli, C. and Mantovani, A. (2013), "Identification and management of toxicological hazards of street foods in developing countries", Food and Chemical Toxicology, Vol. 63, pp. 143-152.

Rane, S. (2011), "Street vended food in developing world: hazard analyses", Indian Journal of Microbiology, Vol. 51 No. 1, pp. 100-106.

Regulation, E.C. (2004), No 852/2004 of the European Parliament and of the Council of 29 April 2004 on the Hygiene of Foodstuffs, European Union, available at: https:/eur-lex.europa.eu/legalcontent/EN/TXT/?uri=celex:32004R0852.

Roever, S. (2014), Informal Economy Monitoring Study Sector Report: Street Vendors. Women in Informal Employment Globalizing and Organizing (WIEGO), Cambridge, MA, available at: https://www.wiego.org/sites/default/files/publications/files/IEMS-Sector-Full-Report-StreetVendors.pdf (accessed 27 October 2020).

Sabbithi, A., Reddi, S.G.D.N.L., Naveen Kumar, R., Bhaskar, V., Subba Rao, G.M. and Rao, V., S. (2017), "Identifying critical risk practices among street food handlers", British Food Journal, Vol. 119 No. 2, pp. 390-400.

Street food vendors in Slovenia 
BFJ

123,13

120
Samapundo, S., Climat, R., Xhaferi, R. and Devlieghere, F. (2014), "Food safety knowledge, attitudes and practices of street food vendors and consumers in Port-au-Prince, Haiti”, Food Control, Vol. 50, pp. 457-466.

Trafialek, J., Drosinosb, H.E. and Kolanowskic, W. (2017), "Evaluation of street food vendors' hygienic practices using fast observation questionnaire”, Food Control, Vol. 80, pp. 350-359.

Trafialek, J., Drosinos, H.E. and Laskowskia, W. (2018), "Street food vendors' hygienic practices in some Asian and EU countries - a survey", Food Control, Vol. 85, pp. 212-222.

WHO (1996), Essential Safety Requirements for Street-Vended Foods (Revised Edition), Food Safety Unit, Division of Food and Nutrition, World Health Organization, Geneva, available at: https:// apps.who.int/iris/bitstream/handle/10665/63265/WHO_FNU_FOS_96.7.pdf?sequence $=1$ (accessed 3 August 2020). 
Appendix

1. General characteristics

Date and time of observation

Location

(1) City centre

Type of facility

Type of food

Number of employees

(1) Food truck

(1) Meat or fish meals

Gender (M) : (F)

2. Hygienic-technical requirements and evaluation criteria

Visual cleanliness

Insects/pests

Waste management

Glass protection

Water supply

Physical barriers

Usage of appropriate materials

Table tops
Are equipment, utensils, and working surfaces that come into direct contact with food (visually) clean?

All equipment has to be in good condition. Adequate maintenance and cleaning have to be ensured

Are there any insects and/or other pests visible in the working place or near it?

Facilities should be protected from the invasion of insects and pests. The hygienic disposal of waste should be ensured

Is food waste deposited in closable containers and eliminated in a hygienic way? Is all waste removed from working surfaces as quickly as possible, to avoid their accumulation?

Waste should be collected in separate containers. Waste containers should be kept clean to minimize pest attraction. Food waste should be removed as quickly as possible from foodhandling areas

Are lighting sources protected by fixtures to ensure that food is not contaminated by small glass particles in case of breakages? All lighting sources should be protected by shatterproof covers Is an adequate supply of potable water available?

Supply of potable water should always be available Is the food separated from the consumer to reduce the risk of cross-contamination?

The food has to be protected against any contamination that is likely to render the food unfit for human consumption

Are equipment and utensils that come into direct contact with food made out of smooth, inert to the food and non-absorbent materials so that adequate maintenance, cleaning and the minimization of air-borne contamination is ensured?

All equipment and utensils must be made of suitable food contact materials

Are working surfaces that come into direct contact with food in sound condition, durable and easy to clean, and disinfect? The working surface materials should be non-absorbent, non-toxic and inert to food, detergents and disinfectants

Working surfaces that come into direct contact with food should be undamaged, in good condition, and easy to clean. The materials must be accompanied by adequate certificates for food contact
GRADE $(2,3$ 4,5 , or N.O.) 


\section{$\mathrm{BFJ}$ 123,13}

Surface cleaning

Storage and suitability of serving material

Temperaturecontrolled conditions

Food separation

Separation of utensils

Contamination risk

Unnecessary personal items
Is cleaning and/or disinfecting of surfaces that may cause chemical contamination of the food performed during the food preparation?

Cleaning chemicals must be clearly labelled and stored appropriately. Cleaning activities should be carried out in such a way as to avoid food contamination

Are packing materials that are meant to pack food kept separately so that they are not at risk of being contaminated?

Packing materials must be stored separately from food in such a way that the risk of cross-contamination is eliminated

Are suitable temperature-controlled handling and storage conditions for maintaining foodstuffs at appropriate temperatures provided? The cold chain is not to be interrupted

Food storage and handling conditions must be in the accordance with the required temperature regime for all types of food at all stages of food preparation

Are raw foods stored separately from processed foods?

Cross-contamination of raw and processed foods must be avoided Are utensils used separately in accordance with their intended use?

Utensils should be specified for the intended use

Is the risk of food contamination prevented at all stages of food handling?

Appropriate measures should be applied to ensure that food contamination is prevented at all stages of food handling Are there any unnecessary personal items brought into food handling areas? (mobile, phones, wallets, keys. . .)

Personal belongings should only be stored and used in designated areas

3. Personal hygiene requirements and evaluation criteria

Health symptoms (cough or sneeze)

Clean hands/without visible cuts

Do food handlers sneeze, cough, or have other visible discharges from the ear, eye, or nose?

Food handlers with signs or symptoms of illness should not be engaged in food handling activities

Are there any visible scratches, cuts, or wounds on the food handlers' hands?

Cuts and skin abrasions should be covered by a coloured plaster. Disposable gloves should be worn

Clean nails

Visible jewellery

Suitably located washbasins

Handwashing
Are food handlers' nails visibly clean, and not varnished or artificial?

Food handlers' nails should not be false if they pose a threat to the safety of food

Do food handlers wear jewellery on their hands, face, and/or ears during the food handling activities?

Visible jewellery and watches should not be worn

Is there a washbasin intended for hygienic handwashing located and available?

An adequate washbasin for cleaning hands must be located

Do food handlers wash hands frequently enough, using appropriate handwashing technique? (including use of soap) Food handlers should wash their hands regularly, especially when personal cleanliness may affect food safety. Hands should be washed with soap and water. Hand sanitizers should not replace hand washing
GRADE $(2,3$, 4,5 , or N.O.)

\section{Table A1.}


Hand-drying

Wearing gloves

Covered hair

Face touching

Eating during food preparation
Do food handlers perform hygienic hand drying after washing hands and/or wearing gloves?

Hands should be dry in a manner that does not decontaminate the hands

Do food handlers use disposable gloves hygienically during food handling activities?

If gloves are worn, appropriate measures should be applied to ensure the gloves do not become a source of contamination. Food handlers who are wearing gloves should clean their hands regularly

Do food handlers wear suitable protective hair coverings?

During food handling activities, hair should be covered completely, so that food contamination is prevented

Do food handlers touch their face, nose, ears and/or hair during food preparation?

Hands should be washed after touching the face or blowing the nose

Do food handlers eat, drink, or chew during the food preparation?

A designated area intended for eating must be available

Note(s): N.O. - Not observed; 5 - the requirement was fully met; 4-there was a slight deviation in fulfilment of the requirement; 3 - the requirement was not met properly; 2 - the requirement was noncompliant

Table A1.

\section{Corresponding author}

Andrej Ovca can be contacted at: andrej.ovca@zf.uni-1j.si

For instructions on how to order reprints of this article, please visit our website: 